\title{
Minithoracoscopy: A Complementary Technique for Medical Thoracoscopy
}

\author{
Gian Franco Tassi Gian Pietro Marchetti Valentina Pinelli \\ Divisione di Pneumologia, Spedali Civili di Brescia, Brescia, Italia
}

\section{Key Words}

Minithoracoscopy $\cdot$ Medical thoracoscopy $\cdot$ Pleural effusion

\begin{abstract}
Minithoracoscopy, currently defined as thoracoscopy with instruments of a diameter between 2 and $5 \mathrm{~mm}$, is part of the general evolution of endoscopy towards mini-invasiveness. Its most relevant indications in the field of medical thoracoscopy are small effusions, pleural effusions in patients with narrow intercostal spaces and suspected tuberculous pleurisy in areas of low incidence of tuberculosis. In general, it increases the versatility of medical thoracoscopy.
\end{abstract}

Copyright $\odot 2011$ S. Karger AG, Basel

\section{Introduction}

Minithoracoscopy belongs to the field of endoscopy with small-caliber instruments with the objective of mini-invasiveness to reduce the traumatism caused by endoscopic procedures. It can be currently defined as endoscopy with instruments of a diameter between 2 and $5 \mathrm{~mm}$ to distinguish it from micro-/needle endoscopy [1].

Previous interventions with small endoscopes were mainly performed in laparoscopy $[2,3]$ and subsequently in endoscopic surgery on various organs and diseases [4-6] including lung and pleural diseases, in particular for pneumothorax $[7,8]$, but also for diagnostic purposes [9-13].

\section{Instruments}

The most important characteristics of instruments to allow an acceptable endoscopic examination to be performed are good illumination and sufficient definition of images, which depend mainly on the caliber of the optics. Even though minithoracoscopes are quite small, they are sufficient to explore the pleural cavity, especially in the presence of small effusions. This is mainly due to the transmission of light through the Hopkins rod-lens system which remains the best system to obtain an acceptable depth of field and good visibility.

The basic instruments commonly used are trocars, optics and forceps (fig. 1).

Metal trocars are preferable, being autoclavable and reusable for years; normally they have a caliber of about $4 \mathrm{~mm}$ with a pointed stylet. The optics is about $3 \mathrm{~mm}$ in diameter and $25 \mathrm{~cm}$ in length. Generally, two optics $\left(0^{\circ}\right.$ and $\left.30^{\circ}\right)$ are sufficient to achieve adequate examination of the cavity.

The forceps commonly used have a 3-mm diameter with a sufficient opening, at least $5 \mathrm{~mm}$, since the volumes of the biopsies depend on the size of the opening. Rotating forceps are preferable because they permit easier performance of biopsies. Other accessory instruments are now available, such as scissors to resect adhesions, needles to aspirate material for cytological examination and aspiration/irrigation cannulae to treat infection of the pleural space.

\section{Technique}

Minithoracoscopy is performed using two trocars, one for the endoscope and one for the bioptic forceps or accessory instruments. It is carried out under simple local anesthesia with sedation by midazolam. It is also possible to use propofol as con-

\section{KARGER}

Fax +41613061234

E-Mail karger@karger.ch

www.karger.com
(C) 2011 S. Karger AG, Basel

0025-7931/11/0822-0204\$38.00/0

Accessible online at:

www.karger.com/res
Gian Franco Tassi

Divisione di Pneumologia, Spedali Civili di Brescia

Piazzale Spedali Civili 1

IT-25103 Brescia (Italy)

Tel. +39030 399 5591, E-Mail gf.tassi@tin.it 
Fig. 1. Basic instruments used in minithoracoscopy.

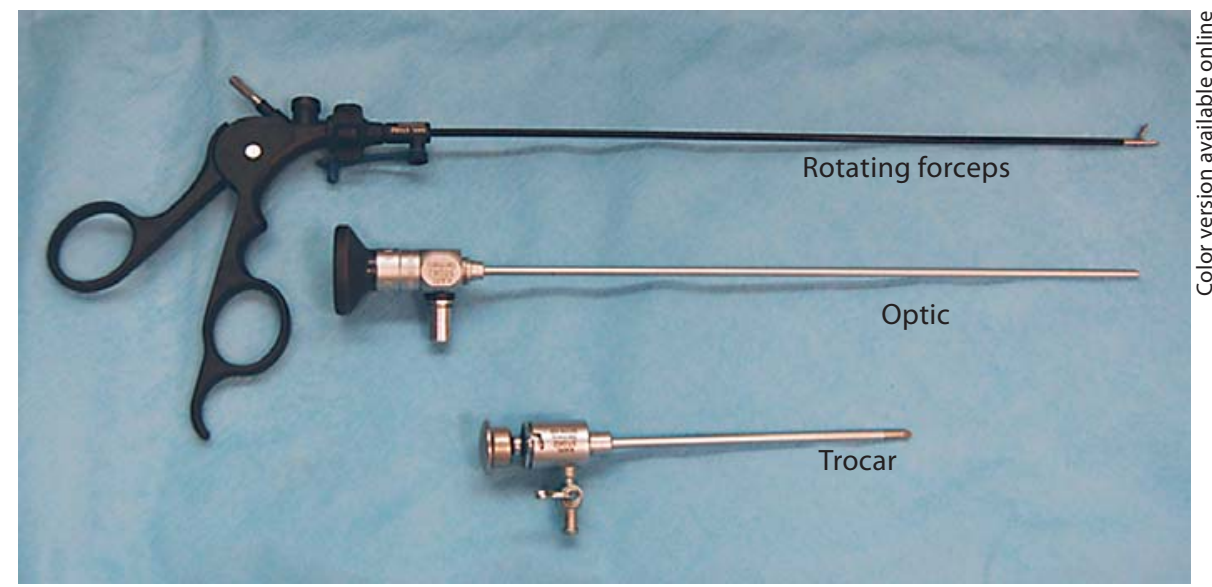

2

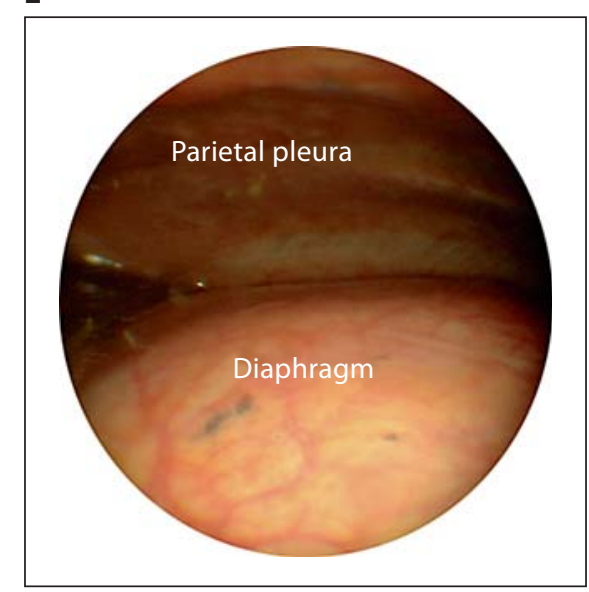

3

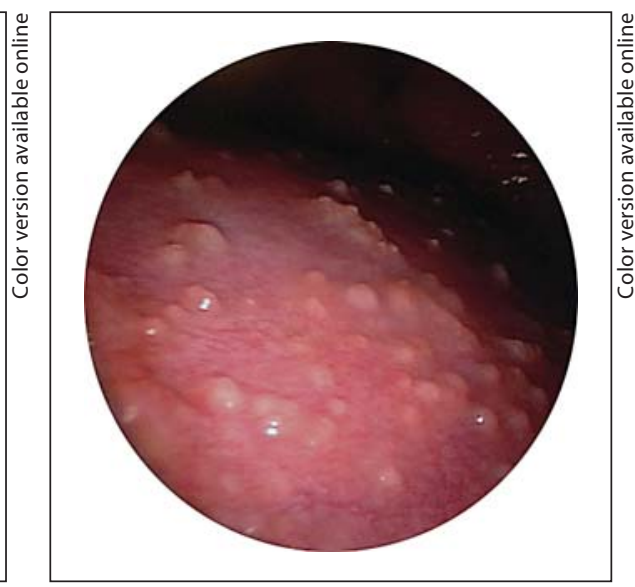

Fig. 2. Minithoracoscopic appearance of parietal pleura and diaphragm with mild inflammation.

Fig. 3. Minithoracoscopic appearance of nodules (histologically tuberculous) on the diaphragm.

tinuous infusion or boluses. It is advisable, especially for small effusions, to choose the first entry point for the optics by ultrasonography that is performed directly on the endoscopy table with the patient lying in lateral decubitus on the healthy side. After introduction of the first trocar, the liquid is aspirated, the air enters and the cavity can be explored (fig. 2, 3).

Biopsies or other operating maneuvers, such as removal of adhesions, are made through a second trocar introduced in an adjacent intercostal space, under visual control. At the end of the examination, a small drain is placed. It is removed after a few hours following a chest radiograph.

\section{Indications and Results}

In our experience, minithoracoscopy was primarily applied to deal with small effusions, which are frequently inaccessible with the standard 7- or 10 -mm equipment. We have also applied it in patients of small stature and in elderly patients with effusions or in patients with rectracting pleurisy. All of them are characterized by narrow intercostal spaces in which the introduction of a 4-mm trocar is easier. The method is also suitable in suspected tuberculous effusion as an alternative to closed needle biopsy; the invasivity is almost similar, with the advantage of visual identification of the lesions. This is advisable in particular in areas of low incidence of tuberculosis where the thoracoscopic approach should be considered as the diagnostic 'gold standard' and should be performed as soon as possible since even laboratory tests such as adenosine deaminase may not be conclusive [14].

A further possible application is the evaluation of accessibility of the pleural space in case of multiple adhesions, in order to enable safe examination with the standard larger-caliber instrument.

Series of cases examined with small instruments for diagnostic purposes are still limited [9-13]. However, pleural biopsy yield and incidence of complications are comparable to those obtained using the standard technique. 
Table 1. Advantages and disadvantages of minithoracoscopy

Advantages
Reliable instruments
Easy to use
Good visibility
Less local anesthesia required
Less pain during and after the examination
No sutures required
Disadvantages
Fragile instruments
Necessity of expertise in standard thoracoscopy
Conversion required in some cases
Small size of biopsies
Possible inadequacy of lung biopsy
20\% more time required

\section{Discussion}

To achieve complete evaluation of the method, it is important to compare its advantages and disadvantages (table 1).

Besides the technical value of the instruments described above, the main advantage of the method is its tolerance by the patient: because of the small caliber of the instruments, less local anesthesia is required and the procedure causes less pain during and after the examination. Moreover, no sutures are required and the aesthetic results are excellent.

The main disadvantage of the method lies in the fragility of the optics, which should be used carefully to avoid breakage. Needless to say that the method requires expertise in standard thoracoscopy, but it should also be remembered that minithoracoscopy is complementary to the standard technique and that in some cases conversion is required. The small size of the biopsy is not a problem because it can be compensated for by a larger number of samples; on the other hand, the possible inadequacy of lung biopsy can be avoided by careful use of the electrocautery.

In minithoracoscopy, perhaps more than in standard thoracoscopy, ultrasonographic guidance plays an essential role to safely approach small effusions, correctly introduce the trocar even in the presence of a very small effusion when the 'gliding sign' (the respiratory movements of parietal and visceral pleura) is present.

\section{Conclusion}

Minithoracoscopy can be considered as a complementary technique to the standard method for medical thoracoscopy [15]; it can be applied for small effusions that are inaccessible to standard equipment and is well tolerated by patients with narrow intercostal spaces. Moreover, it can be recommended when tuberculous pleurisy is suspected, especially in low-incidence areas.

Generally speaking, it can be seen as an endoscopic tool in interventional pulmonology [16] that increases the versatility and adaptability of thoracoscopy on a case-bycase basis.

\section{References}

1 Tu FF, Advincula AP: Miniaturizing the laparoscope: current applications of micro- and minilaparoscopy. Int $\mathrm{J}$ Gynaecol Obstet 2008;100:94-98.

$\checkmark 2$ Bruhat MA, Goldchmit R: Minilaparoscopy in gynecology. Eur J Obstet Gynecol Reprod Biol 1998;76:207-210.

3 Schauer PR, Ikramuddin S, Luketich JD: Minilaparoscopy. Semin Laparosc Surg 1999;6:21-31.

4 El-Dhuwaib Y, Hamade AM, Issa ME, Balbisi BM, Abid G, Ammori BJ: An 'all 5-mm ports' selective approach to laparoscopic cholecystectomy, appendectomy, and antireflux surgery. Surg Laparosc Endosc Percu$\tan$ Tech 2004;14:141-144.

5 Gagner M, Inabnet WB 3rd: Endoscopic thyroidectomy for solitary thyroid nodules. Thyroid 2001;11:161-163.
Rajan P, Turna B: New trends in minimally invasive urological surgery. Int Braz J Urol 2009;35:514-520.

-7 Yoon YH, Kim KH, Han JY, Baek WK, Lee CS, Kim JT: Management of persistent or recurrent pneumothorax with a two millimeter mini-video-thoracoscope. J Korean Med Sci 2000;15:507-509.

${ }_{8}$ Chen JS, Hsu HH, Kuo SW, Tsai PR, Chen RJ, Lee JM, Lee YC: Needlescopic versus conventional video-assisted thoracic surgery for primary spontaneous pneumothorax: a comparative study. Ann Thorac Surg 2003; 75:1080-1085.

-9 D’Alessandro AA: Microthoracoscopy: at the cutting edge of thoracic surgery. J Laparoendosc Adv Surg Tech 1997;7:313-318.

10 Malthaner RA, Inculet RI: Minithoracoscopy for pleural effusions. Can Respir J 1998;5: 253-254.
1 Lazopoulos G, Kotoulas C, Kokotsakis J, Foroulis C, Lioulias A: Diagnostic mini-video assisted thoracic surgery. Effectiveness and accuracy of new generation $2.0 \mathrm{~mm}$ instruments. Surg Endosc 2002;16:1793-1795.

12 Tassi G, Marchetti G: Minithoracoscopy: a less invasive approach to thoracoscopy. Chest 2003;124:1975-1977.

13 Janssen JP, Thunnissen F, Visser F: Comparison of the $2.0 \mathrm{~mm}$ and the $3.5 \mathrm{~mm}$ minithoracoscopy set to standard equipment for medical thoracoscopy. Eur Respir J 2003;22(suppl 45):S451.

14 Loddenkemper R. Thoracoscopy: state of the art. Eur Respir J 1998;11:213-221.

15 Rodríguez-Panadero F. Medical thoracoscopy. Respiration 2008;76:363-372.

16 Lee P, Mathur PN, Colt HG. Advances in thoracoscopy: 100 years since Jacobaeus. Respiration 2010;79:177-186. 